\title{
Article \\ Polymyxin B Combined with Minocycline: A Potentially Effective Combination against blaOXA-23-harboring CRAB in In Vitro PK/PD Model
}

\author{
Xingyi Qu ${ }^{1,2,3,4,+}$, Xingchen Bian ${ }^{1,2,3,5,+}$, Yuancheng Chen ${ }^{3,4}$, Jiali $\mathrm{Hu}^{1,2,3}$, Xiaolan Huang ${ }^{1,2,3}$, Yu Wang ${ }^{1,2,3}$, \\ Yaxin Fan ${ }^{1,2,3}$, Hailan Wu ${ }^{1,2,3}$, Xin Li ${ }^{1,2,3}$, Yi Li ${ }^{1,2,3}$, Beining Guo ${ }^{1,2,3}$, Xiaofen Liu ${ }^{1,2,3, *}$ and Jing Zhang $1,2,3,4, *$ (i) \\ 1 Institute of Antibiotics, Huashan Hospital, Fudan University, Shanghai 200040, China; \\ 20111030085@fudan.edu.cn (X.Q.); bxc19940216@163.com (X.B.); hujialifudan@163.com (J.H.); \\ xlanhuang@163.com (X.H.); 13917658241@163.com (Y.W.); fanyaxin20080908@126.com (Y.F.); \\ mswuhl@163.com (H.W.); 1xxj6311@163.com (X.L.); 85773627@163.com (Y.L.); 13045666468@163.com (B.G.) \\ 2 Key Laboratory of Clinical Pharmacology of Antibiotics, Shanghai 200040, China \\ 3 National Health Commission \& National Clinical Research Center for Aging and Medicine, \\ Huashan Hospital, Fudan University, Shanghai 200040, China; cyc_1983@163.com \\ 4 Phase I Unit, Huashan Hospital, Fudan University, Shanghai 200040, China \\ 5 Department of Biological Medicines \& Shanghai Engineering Research Center of Immunotherapeutics, \\ School of Pharmacy, Fudan University, Shanghai 201203, China \\ * Correspondence: liuxiaofen227@163.com (X.L.); zhangj_fudan@aliyun.com (J.Z.); Tel.: +86-21-52888190 (J.Z.) \\ + These authors contributed equally to the manuscript.
}

check for updates

Citation: Qu, X.; Bian, X.; Chen, Y.; Hu, J.; Huang, X.; Wang, Y.; Fan, Y.; Wu, H.; Li, X.; Li, Y.; et al. Polymyxin B Combined with Minocycline: A Potentially Effective Combination against blaOXA-23-harboring CRAB in In Vitro PK/PD Model. Molecules 2022, 27, 1085. https://doi.org/ $10.3390 /$ molecules 27031085

Academic Editor: Chongshan Dai

Received: 30 December 2021

Accepted: 1 February 2022

Published: 6 February 2022

Publisher's Note: MDPI stays neutral with regard to jurisdictional claims in published maps and institutional affiliations.

Copyright: (c) 2022 by the authors. Licensee MDPI, Basel, Switzerland. This article is an open access article distributed under the terms and conditions of the Creative Commons Attribution (CC BY) license (https:// creativecommons.org/licenses/by/ $4.0 /)$.

\begin{abstract}
Polymyxin-based combination therapy is commonly used to treat carbapenem-resistant Acinetobacter baumannii (CRAB) infections. In the present study, the bactericidal effect of polymyxin $B$ and minocycline combination was tested in three CRAB strains containing blaOXA-23 by the checkerboard assay and in vitro dynamic pharmacokinetics/pharmacodynamics (PK/PD) model. The combination showed synergistic or partial synergistic effect (fractional inhibitory concentration index $\leq 0.56)$ on the tested strains in checkboard assays. The antibacterial activity was enhanced in the combination group compared with either monotherapy in in vitro PK/PD model. The combination regimen (simultaneous infusion of $0.75 \mathrm{mg} / \mathrm{kg}$ polymyxin $\mathrm{B}$ and $100 \mathrm{mg}$ minocycline via $2 \mathrm{~h}$ infusion) reduced bacterial colony counts by $0.9-3.5 \log _{10}$ colony forming units per milliliter $(\mathrm{CFU} / \mathrm{mL})$ compared with either drug alone at $24 \mathrm{~h}$. In conclusion, $0.75 \mathrm{mg} / \mathrm{kg}$ polymyxin B combined with $100 \mathrm{mg}$ minocycline via $2 \mathrm{~h}$ infusion could be a promising treatment option for CRAB bloodstream infections.
\end{abstract}

Keywords: Acinetobacter baumannii; polymyxin B; minocycline; combination therapy; in vitro pharmacokinetic/pharmacodynamic model

\section{Introduction}

Bloodstream infections are most common (37/131 studies, 28\%) severe infections among reported studies, and Acinetobacter baumannii is the top pathogen (52/131 studies, $38.5 \%$ and $4395 / 11,546$ patients, 38\%) [1]. The mortality of Acinetobacter baumannii-related bloodstream infections showed an increasing trend in a 10-year prospective study in China [2]. There is an urgent need for rational and effective medication schemes to be developed in clinics. Polymyxins have become a last-resort treatment for multi-drug resistant Gram-negative bacterial infections, including Acinetobacter baumannii [3]. Although higher doses resulted in better therapeutic outcomes, greater incidence of toxicity tended to follow, such as nephrotoxicity and neurotoxicity [4]. The adverse effects limited the clinical use of polymyxins and deficient drug doses may induce the development of polymyxin-resistant Gram-negative bacteria [5]. Polymyxins are concentration-dependent antibiotics [6]. The pharmacokinetics/pharmacodynamics (PK/PD) index of polymyxins is polymyxins' area under the concentration-time curve (AUC) divided by minimum inhibitory concentration (MIC), which is $7.4-17.6$ for $2 \log _{10}$ colony forming units per milliliter (CFU/mL) 
decrease against Acinetobacter baumannii in mouse thigh model [7]. In contrast to colistin methanesulfonate (CMS), whose active drug concentration increases slowly in blood after administration, polymyxin B has remarkable advantages in bloodstream infections [8]. Coupled with the fact that heterogeneous resistance of Acinetobacter baumannii occurred when using polymyxin B alone $[9,10]$, polymyxin-based combination therapy is rational and necessary [8].

Minocycline, belonging to tetracyclines, is promising for the treatment of Acinetobacter baumannii infections [11-14]. Minocycline is a time-dependent antibiotic with a long postantibiotic effect (PAE), the PK/PD index of which is AUC/MIC, and the PK/PD targets for $1 \log _{10} \mathrm{CFU} / \mathrm{mL}$ were $23.3 \pm 3.7$ against Acinetobacter baumannii in in vitro studies [15]. A study initiated by the Antimicrobial Stewardship Program (ASP) found that minocycline was safe and effective for patients infected with multi-drug resistant Acinetobacter baumannii (MDRAB) [16]. Several in vitro and in vivo studies have demonstrated synergistic effects and potential mortality decreases of the combination of polymyxin $B$ and minocycline [17-20]. Polymyxin B and minocycline combination not only had a partial synergy in checkerboard assay with the fractional inhibitory concentration index (FICI) value of 0.75 [17], but also prolonged the survival time of the lung-infection mice [17,18].

However, most previous studies on the combined efficacy of polymyxin B and minocycline against Acinetobacter baumannii were limited to checkerboard assays and static time-kill curves [18-20], rarely considering the dynamic changes of drugs' pharmacokinetics in the human body. Therefore, the present study simulated the pharmacokinetics of polymyxin B and minocycline against Acinetobacter baumannii bloodstream infection in in vitro dynamic PK/PD models. The bactericidal effects are expected to provide important information for optimizing dosing regimens for this combination against carbapenem-resistant Acinetobacter baumannii (CRAB).

\section{Results}

\subsection{Genetic Information, MICs, and Checkboard Assays}

The genetic information of the three strains has been analyzed through whole-genome sequencing [21], as shown in Table 1. The three strains have different multilocus sequence typing (MLST) subtypes, namely, ST195, ST208, and ST191, which were the dominant sequence types in Acinetobacter baumannii [21]. All the three strains had the $\operatorname{lp} x \mathrm{C}$ and $\operatorname{lp} x A$ genes without mutations. The three strains were intermediate to polymyxin $\mathrm{B}$ (according to CLSI, M100-S31, 2021) with MICs of 0.5, 0.5, and $0.25 \mathrm{mg} / \mathrm{L}$, respectively (Table 2). All the three strains harboring the tet $A$ gene that encodes resistance to tetracycline were resistant to doxycycline (MICs were $64 \mathrm{mg} / \mathrm{L}$ for all the strains), susceptible to minocycline for AB070311 and AB170428, and intermediate for AB162487. The genome annotation revealed that all the strains contained multiple antibiotic resistance genes including OXA23, OXA-66 encoding the beta-lactamase resistance, which are consistent with the MICs over $16 \mathrm{mg}$ /L for meropenem and doripenem. The three strains also had high MICs for aztreonam $(\mathrm{MICs}=64 \mathrm{mg} / \mathrm{L})$ and cefoperazone $(\mathrm{MICs}>256 \mathrm{mg} / \mathrm{L})$, which were consistent with the ARO gene, TEM-1, for example.

Checkboard assays showed that one strain (AB162487) had a synergistic effect of polymyxin B and minocycline with a FICI value of 0.375 . The other two strains (AB070311 and AB170428) showed partial synergistic effects of polymyxin B and minocycline, and the FICI values were 0.56 (Table 2). 
Table 1. Genetic information of tested CRAB strains.

\begin{tabular}{|c|c|c|c|c|}
\hline ARO Name & AB070311 & AB170428 & AB162487 & Antimicrobial Agents' Classes \\
\hline $\begin{array}{l}\operatorname{lp} x C \\
\operatorname{lp} x A\end{array}$ & $\begin{array}{l}\sqrt{ } \\
\sqrt{ }\end{array}$ & $\begin{array}{l}\sqrt{ } \\
\sqrt{ }\end{array}$ & $\begin{array}{l}\sqrt{ } \\
\sqrt{ }\end{array}$ & peptide antibiotic \\
\hline $\begin{array}{c}\text { tet } A \\
\text { tetR } \\
\text { adeA } \\
\text { adeB } \\
\text { adeC } \\
\text { adeR } \\
\text { adeS } \\
\text { adeF } \\
\text { adeG } \\
\text { adeH } \\
\text { adeL } \\
\text { adeN } \\
\text { adeI } \\
\text { adeJ } \\
\text { adeK } \\
\text { MexK } \\
\text { rpsJ }\end{array}$ & $\begin{array}{l}\sqrt{ } \\
\sqrt{ } \\
\sqrt{ } \\
\sqrt{ } \\
\sqrt{ } \\
\sqrt{ } \\
\sqrt{ } \\
\sqrt{ } \\
\sqrt{ } \\
\sqrt{ } \\
\sqrt{ } \\
\sqrt{ } \\
\sqrt{ } \\
\sqrt{ } \\
\sqrt{ } \\
\sqrt{ } \\
\sqrt{ }\end{array}$ & $\begin{array}{l}\sqrt{ } \\
\sqrt{ } \\
\sqrt{ } \\
\sqrt{ } \\
\sqrt{ } \\
\sqrt{ } \\
\sqrt{ } \\
\sqrt{ } \\
\sqrt{ } \\
\sqrt{ } \\
\sqrt{ } \\
\sqrt{ } \\
\sqrt{ } \\
\sqrt{ } \\
\sqrt{ } \\
\sqrt{ }\end{array}$ & $\begin{array}{l}\sqrt{ } \\
\sqrt{ } \\
\sqrt{ } \\
\sqrt{ } \\
\sqrt{ } \\
\sqrt{ } \\
\sqrt{ } \\
\sqrt{ } \\
\sqrt{ } \\
\sqrt{ } \\
\sqrt{ } \\
\sqrt{ } \\
\sqrt{ } \\
\sqrt{ } \\
\sqrt{ } \\
\sqrt{ }\end{array}$ & $\begin{array}{l}\text { tetracycline antibiotic; fluoroquinolone antibiotic } \\
\text { tetracycline antibiotic; fluoroquinolone antibiotic; } \\
\text { cephalosporin; macrolide antibiotic; carbapenem; rifamycin } \\
\text { antibiotic; lincosamide antibiotic; diaminopyrimidine } \\
\text { antibiotic; phenicol antibiotic; penem } \\
\text { tetracycline antibiotic; triclosan; macrolide antibiotic } \\
\text { tetracycline antibiotic }\end{array}$ \\
\hline $\begin{array}{c}\text { OXA-66 } \\
\text { OXA-366 } \\
\text { OXA-23 } \\
\text { TEM-1 } \\
\text { Acinetobacter baumannii } \\
\text { OprD conferring } \\
\text { resistance to imipenem } \\
\text { carO } \\
\text { ADC- } 61 \\
\text { ADC-78 }\end{array}$ & $\begin{array}{l}\sqrt{ } \\
\sqrt{ } \\
\sqrt{ }\end{array}$ & $\begin{array}{l}\sqrt{ } \\
\sqrt{ } \\
\sqrt{ } \\
\sqrt{ }\end{array}$ & $\begin{array}{l}\sqrt{ } \\
\sqrt{ } \\
\sqrt{ } \\
\sqrt{ } \\
\sqrt{ } \\
\sqrt{ }\end{array}$ & $\begin{array}{c}\text { cephalosporin; penam } \\
\text { cephalosporin; penam; penem; monobactam } \\
\text { cephalosporin; penam; penem; monobactam; carbapenem; } \\
\text { cephamycin } \\
\text { carbapenem } \\
\text { cephalosporin }\end{array}$ \\
\hline MLST & ST195 & ST208 & ST191 & \\
\hline
\end{tabular}

ARO, Antibiotic Resistance Ontology; tet, tigecycline resistance gene; MLST, multilocus sequence typing.

Table 2. MICs and FICI values of tested CRAB strains.

\begin{tabular}{cccc}
\hline $\begin{array}{c}\text { Antimicrobial } \\
\text { Agents }\end{array}$ & AB070311 & AB170428 & AB162487 \\
\hline polymyxin B & $0.5(\mathrm{I})$ & $0.5(\mathrm{I})$ & $0.25(\mathrm{I})$ \\
minocycline & $4(\mathrm{~S})$ & $4(\mathrm{~S})$ & $8(\mathrm{I})$ \\
doxycycline & $64(\mathrm{R})$ & $64(\mathrm{R})$ & $64(\mathrm{R})$ \\
meropenem & $64(\mathrm{R})$ & $16(\mathrm{R})$ & $16(\mathrm{R})$ \\
doripenem & $64(\mathrm{R})$ & $32(\mathrm{R})$ & $16(\mathrm{R})$ \\
aztreonam * & 64 & 64 & 64 \\
cefoperazone * & $>256$ & $>256$ & $>256$ \\
sulbactam * & 16 & 16 & 16 \\
\hline FICI(PMB/MINO) & 0.56 & 0.56 & 0.375 \\
\hline
\end{tabular}

CRAB, carbapenem-resistant Acinetobacter baumannii; MIC, minimal inhibitory concentration, presented in $\mathrm{mg} / \mathrm{L}$ FICI(PMB/MINO), fractional inhibitory concentration index of polymyxin B and minocycline combination; $\mathrm{S}$, susceptibility; I, intermediacy; R: resistance. *: CLSI does not provide susceptibility breakpoints for aztreonam, cefoperazone, and sulbactam.

\subsection{Dynamic PK/PD Model}

\subsubsection{Concentration Verification}

In the dynamic PK/PD model, the concentrations of polymyxin B $(0.75 \mathrm{mg} / \mathrm{kg}$ intravenously administration with $2 \mathrm{~h}$ infusion) and minocycline (100 $\mathrm{mg}$ intravenously administration with $2 \mathrm{~h}$ infusion) in the central compartment were within $\pm 30 \%$ of the target concentrations (except minocycline at $24 \mathrm{~h}$ ) as verified by LC-MS/MS (Figure 1). 

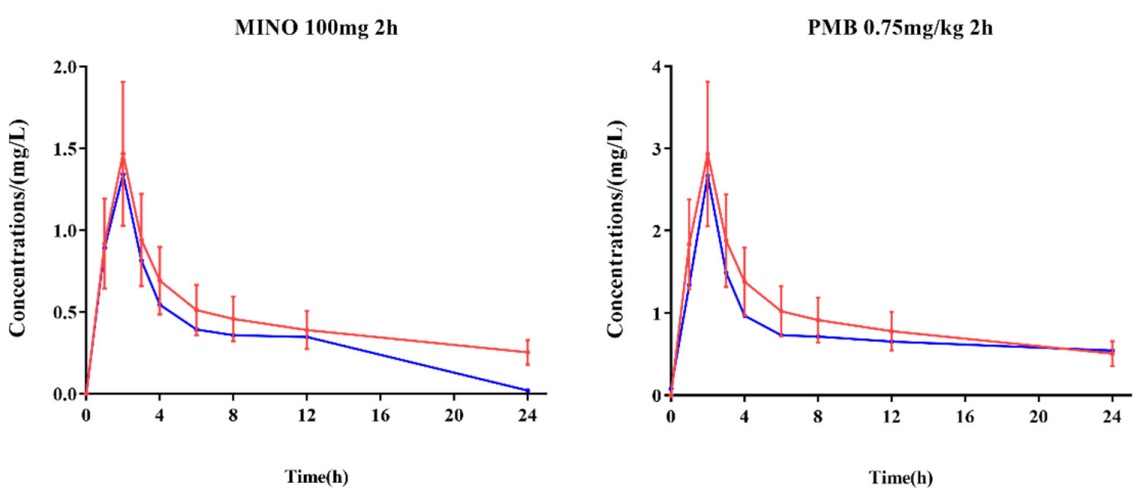

Figure 1. Comparison of target concentrations in human subjects and measured concentrations in the central compartment of in vitro PK/PD model. Red lines: target concentrations in vitro; blue lines: measured concentrations; error limit (red): $\pm 30 \%$ of target concentrations.

\subsubsection{Time-Kill Curves}

The colony counts of the three strains were recorded under different dosing regimens (Figure 2). The single dosing regimen of polymyxin B (pharmacokinetics corresponding to $0.75 \mathrm{mg} / \mathrm{kg} 2 \mathrm{~h}$ infusion in bloodstream infection patients) showed antibacterial activity for the first $2 \mathrm{~h}$, with the colony counts approximately decreased 3-4 $\log _{10} \mathrm{CFU} / \mathrm{mL}$ (range from -3.74 to $-3.17 \log _{10} \mathrm{CFU} / \mathrm{mL}$ ). However, the colony count then increased to the initial inoculum level in the following $22 \mathrm{~h}$. The colony counts of single dosing regimen of minocycline (pharmacokinetics corresponding to $100 \mathrm{mg}$ via $2 \mathrm{~h}$ infusion in healthy volunteers) resulted $1.6 \log _{10} \mathrm{CFU} / \mathrm{mL}$ increase in average (ranging from 1.16 to $1.85 \log _{10} \mathrm{CFU} / \mathrm{mL}$ ) in $24 \mathrm{~h}$. Nevertheless, the combination regimen of polymyxin B $(0.75 \mathrm{mg} / \mathrm{kg}, 2 \mathrm{~h}$ infusion $)$ and minocycline (100 mg, $2 \mathrm{~h}$ infusion) demonstrated significantly enhanced antibacterial activity over a $24 \mathrm{~h}$ period, with the colony counts decreasing more than $4 \log _{10} \mathrm{CFU} / \mathrm{mL}$ at $3 \mathrm{~h}$ (below the limit of detection).
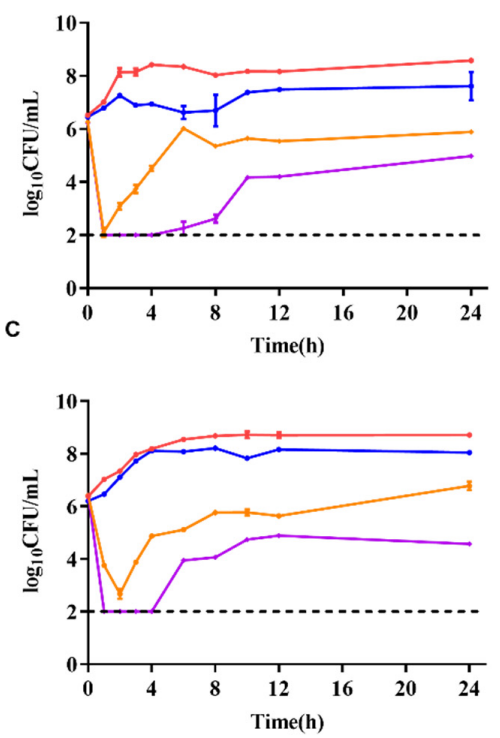

B
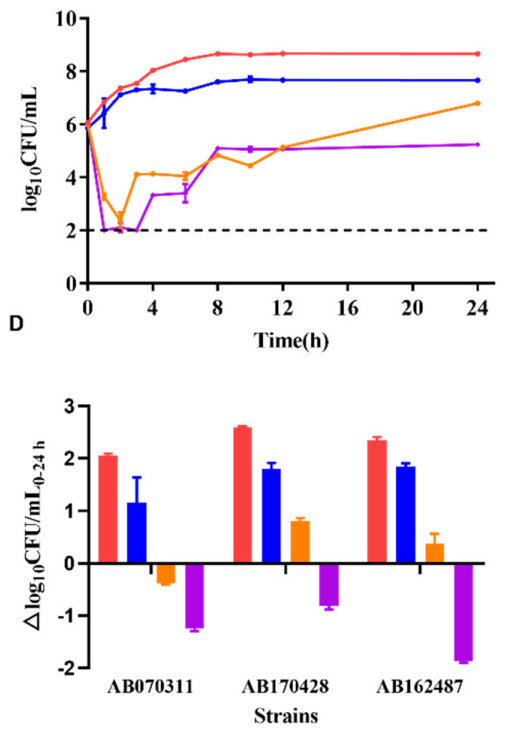

Figure 2. Time-kill curves of polymyxin $B$ and minocycline alone and in combination against CRAB strains in a dynamic PK/PD model. (A): Time-kill curves of AB070311, (B): time-kill curves of AB170428, (C): time-kill curves of AB162487, (D): colony counts changed in the range of 0-24 h; red lines or column: bacterial growth curve; blue lines or column: minocycline $100 \mathrm{mg}$ via $2 \mathrm{~h}$ infusion; orange lines or column: polymyxin B $0.75 \mathrm{mg} / \mathrm{kg}$ via $2 \mathrm{~h}$ infusion; purple lines or column: minocycline $100 \mathrm{mg}$ combined polymyxin B $0.75 \mathrm{mg} / \mathrm{kg}$ via $2 \mathrm{~h}$ infusion; dash line: the detection limit. 
As shown in Figure 2, for the combination therapy, despite a rebound occurring after $3 \mathrm{~h}$, the average colony counts were still decreased by $1.3 \log { }_{10} \mathrm{CFU} / \mathrm{mL}$ at $24 \mathrm{~h}$ compared with initial counts at $0 \mathrm{~h}$ (ranging from -1.86 to $-0.81 \log _{10} \mathrm{CFU} / \mathrm{mL}$ ), showing superior antibacterial activity and 0.9-3.5 $\log _{10} \mathrm{CFU} / \mathrm{mL}$ compared with either drug alone at $24 \mathrm{~h}$ [22].

\subsubsection{PK/PD Calculation}

The AUCs were 19.07 and $8.61 \mathrm{mg} \cdot \mathrm{h} / \mathrm{L}$ for polymyxin B $(0.75 \mathrm{mg} / \mathrm{kg}$ infusion $)$ and minocycline (100 mg infusion), respectively. The AUC/MICs for polymyxin B and minocycline in monotherapy or combination therapy were calculated in Table 3. In checkboard assays, polymyxin B and minocycline combination decreased MICs by 2-8 folds more than monotherapy did. Therefore, AUC/MIC achieved higher values after combination comparing with that of monotherapy.

Table 3. PK/PD calculations of tested CRAB strains.

\begin{tabular}{ccccccc}
\hline & \multicolumn{2}{c}{ AB070311 } & \multicolumn{2}{c}{ AB170428 } & \multicolumn{2}{c}{ AB163560 } \\
& MIC & AUC/MIC & MIC & AUC/MIC & MIC & AUC/MIC \\
\hline $\begin{array}{c}\text { PMB Alone } \\
\text { PMB Combined with }\end{array}$ & 0.50 & 38.14 & 0.50 & 38.14 & 0.25 & 76.28 \\
MINO & 0.25 & 76.28 & 0.25 & 76.28 & 0.06 & 305.12 \\
$\begin{array}{c}\text { MINO Alone } \\
\text { MINO Combined }\end{array}$ & 4.00 & 2.15 & 4.00 & 2.15 & 8.00 & 1.08 \\
$\quad$ with PMB & 0.25 & 34.42 & 0.25 & 34.42 & 1.00 & 8.61 \\
\hline MINO: minocycline; PMB: polymyxin B. & & & & & &
\end{tabular}

\section{Discussion}

Polymyxin-based combination therapies would be effective treatments for CRAB infections, with higher clinical response rates compared with non-polymyxin based therapies [23]. Zhang et al. [20] performed checkerboard assays and static time-kill curves, and showed that polymyxin B and minocycline had a synergistic or additive effect on pan-drug-resistant Acinetobacter baumannii, with FICI values $\leq 0.5$ (44\%) or in the range of $0.5-1$ (48\%). Another study conducted animal experiments and observed the four-day survival rate of mice. Polymyxin B and minocycline combination extended the survival time in a neutropenic murine pneumonia model [18]. Maya et al. reported a triple therapy combination against CRAB using an in vitro PK/PD model [24] which demonstrated that minocycline (700 mg loading dose plus $350 \mathrm{mg} \mathrm{q12h})$ and polymyxin B $(0.25 \mathrm{mg} / \mathrm{kg}) \mathrm{com}-$ bined with sulbactam ( $9 \mathrm{~g}$, continuous infusion in $24 \mathrm{~h}$ ) could maintain a bactericidal effect for $96 \mathrm{~h}$ with no bacterial regrowth and minimal resistance development [24].

All three strains selected were intermediated to polymyxin B, and two of them were susceptible to minocycline, with one intermediate to minocycline. The MICs of polymyxin $\mathrm{B}$ were equal to the $\mathrm{MIC}_{90}(0.5 \mathrm{mg} / \mathrm{L})$ of 262 Acinetobacter baumannii strains from more than 30 teaching hospitals in China [25]. The susceptibility range of minocycline was 20-62.5\% against Acinetobacter baumannii in Chinese bloodstream infection patients [26]. Hence, all the three strains were typically representative for Acinetobacter baumannii. At the same time, the selected strains were classified as ST195, ST208, and ST191, respectively, which were the typical sequence type isolated from sputum, blood, or urine in a previous study [21]. Meanwhile, the three strains all have blaOXA-23, which has been considered as the most possible reason for carbapenem resistance in Acinetobacter baumannii isolates [21]. For AB070311 and AB170428, Bian et al. [27] performed similar in vitro PK/PD experiments using colistin and sulbactam: $1 \mathrm{mg} / \mathrm{L}$ of colistin and $1 \mathrm{~g}$ of sulbactam effectively reduced bacterial counts by $2 \log _{10} \mathrm{CFU} / \mathrm{mL}$ in $24 \mathrm{~h}$. We simulated the pharmacokinetics of polymyxin $\mathrm{B}$ and minocycline and investigated the antibacterial effect of the combination regimen. Satisfactory results (0.81-1.86 $\log _{10} \mathrm{CFU} / \mathrm{mL}$ decrease at $24 \mathrm{~h}$ ) showed synergy or partial synergy of $0.75 \mathrm{mg} / \mathrm{kg}$ polymyxin B and $100 \mathrm{mg}$ minocycline combination against 
three CRABs in our study. Therefore, polymyxin B combined with minocycline can also be considered as an alternative effective combination approach for treating CRAB. As for PK/PD calculations, MICs in combination are considered more reasonable than MICs in monotherapy. When two antimicrobial agents were used in combination, they had a combined PK/PD index [28]. The tested three strains all achieved the PK/PD target of $2 \log _{10} \mathrm{CFU} / \mathrm{mL}$ reduction (>17.6) for polymyxin B in monotherapy [7]. Unfortunately, none of them reached the PK/PD target $23.3 \pm 3.7$ for minocycline in monotherapy. In combination, not only the AUC/MICs were achieved for polymyxin B, but also AB070311 and AB170428 reached the AUC/MIC target for minocycline.

Although pharmacokinetic parameters of minocycline were obtained from Chinese healthy subjects [29], there were similar pharmacokinetics between patients and healthy subjects [30-32]. Additionally, both polymyxin B and minocycline had similar $\mathrm{T}_{1 / 2}(\sim 12 \mathrm{~h})$ in adult patients $[30,33]$, providing more advantageous combination therapy with similar pharmacokinetic profiles. The extended infusion time was taken into consideration in the present study, and a $2 \mathrm{~h}$ infusion rather than a single injection was performed. The pharmacokinetic simulations of both drugs were based on two-compartment models with parameters of $\mathrm{V}_{1}, \mathrm{~K}_{21}, \alpha$, and $\beta$, so the simulated concentrations were more accurate. Our study demonstrated that a combined infusion of $100 \mathrm{mg}$ minocycline and $0.75 \mathrm{mg} / \mathrm{kg}$ polymyxin B via a $2 \mathrm{~h}$ infusion in humans could lead to the reduction of bacterial burden over $24 \mathrm{~h}$ against three CRAB isolates. However, there were several limitations. Firstly, a single dose was performed, and the bactericidal effect of multiple doses needs further validation. Secondly, our study simulated a combination regimen that both drugs were infused simultaneously rather than sequentially, while both approaches could apply in clinics. Whether sequential infusion could also achieve bacterial burden reduction also needs further investigation. Lastly, the host immune system was not taken into account; there could be an underestimation in the extrapolation of our results to patients with a normal immune system. Therefore, the enhanced bactericidal effects of polymyxin B combined with minocycline in the in vitro PK/PD model still needs to be validated in the clinic.

Possible mechanisms could be explained for the synergy between the combination of polymyxin and minocycline. Firstly, polymyxin B is able to destroy bacterial cell envelope [34], which makes it easier for minocycline to enter into cells and bind to the 30S ribosomal subunit [35], thus inhibiting protein synthesis. Secondly, polymyxin B can interfere with the minocycline efflux pump, resulting in increased intracellular concentrations of minocycline and bactericidal activity [18]. Furthermore, the possible PAE may play an important role in this combination. The PAE of tetracyclines was $>4 \mathrm{~h}$ against Enterobacteriaceae, although unclear against Acinetobacter baumannii [36-38].

Other than the synergistic effect of the polymyxin B and minocycline, the combination may have other advantages. This combination therapy could prolong the survival time of lung-infection mice [18]. Nephrotoxicity and neurotoxicity are the main limitation of polymyxin B application [4,39]. The incidence of polymyxin B-induced neurotoxicityrelated adverse reactions, including perioral paresthesia, dizziness, and numbness of extremities, is much higher in healthy subjects (>70\%) [40]. Minocycline is reported to have strong antioxidant activity through chelating with mitochondrial iron [41], which could inhibit the production of reactive oxygen species (ROS) induced by polymyxins and up-regulate the activities of superoxide dismutase (SOD) and catalase (CAT) to enhance antioxidant capacity of nerve cells [42], thus reducing the polymyxins-induced neurotoxicity. Hence, minocycline was tested for a polymyxin-based combination not only because its antibacterial activity [43], but also because its superiority in alleviating adverse reactions, such as the neurotoxicity of polymyxins $[42,44]$. Of note, the combination could achieve 0.9-3.5 $\log _{10} \mathrm{CFU} / \mathrm{mL}$ with a much lower dose of polymyxin B (1.25-1.5 mg/kg, q12 h [45]), which could be expected to reduce the adverse effect of polymyxin B. However, the safety of the combination in clinics still needs further investigation. 


\section{Materials and Methods}

Polymyxin B (USP, Lot No. R046V0, $1 \mathrm{mg}$ polymyxin B contained $0.734 \mathrm{mg}$ polymyxin B1, $0.086 \mathrm{mg}$ B1-Ile, and $0.090 \mathrm{mg}$ polymyxin B2) and minocycline hydrochloride (Meilunbio ${ }^{\circledR}$, Dalian, China, MB1477-S, purity 98.9\%) were used in this study. Three clinical strains of CRAB isolated from sputum, urine, and blood were studied, detailed clinical information has been described previously [27]. Whole-genome sequencing was employed to investigate the resistant genes and MLST type. Briefly, the genomic DNA was extracted by a Genomic DNA Purification Kit (Tiangen, Beijing, China) according to the production protocol. Sequencing was performed on Illumina Hiseq2500 (Illumina, San Diego, CA, USA). A draft genome was assembled using Velvet (Ver 1.0.15), and resistant genes were searched against "CARD, https: / / card.mcmaster.ca/" database (accessed on 1 October 2021). Multilocus sequence typing (MLST) was performed according to the Oxford scheme. After comparing sequences to the PubMLST database for Acinetobacter baumannii (http:/ / pubmlst.org/abaumannii/ accessed on 1 October 2021), each strain was assigned to the appropriate sequence type.

Minimal inhibitory concentrations (MICs) were determined according to the Clinical and Laboratory Standards Institute (CLSI) guidelines and interpreted according to CLSI breakpoints (CLSI M100-S31, 2021). Checkerboard assays were conducted the same way as that reported by Bian et al. [27]. Synergy was determined by FICI, which is calculated as follows: FICI = MIC PMB when combined with MINO/MIC PMB alone + MIC MINO when combined with PMB/MIC MINO alone [46]. FICI $\leq 0.5$ was assigned as synergy, $0.5<\mathrm{FICI} \leq 0.75$ as partial synergy, $0.75<\mathrm{FICI} \leq 1$ as additive effect, and $>1$ indicated indifferent or antagonistic effect [46].

The in vitro PK/PD model was conducted as previously published [27]. Briefly, the volume of Cation-Adjusted Muller-Hinton Broth (CAMHB) medium in the central compartment was maintained at $200 \mathrm{~mL}$. The initial bacterial inoculum was approximately $6 \log _{10} \mathrm{CFU} / \mathrm{mL}$ and was pre-cultured for $1 \mathrm{~h}$ before dosing. Two reservoirs containing CAMHB or CAMHB with polymyxin B and minocycline were connected to a peristaltic pump (controlled by WinLIN 3.2 software) and used to simulate drug concentrations in the central compartment (as shown in Figure 3).

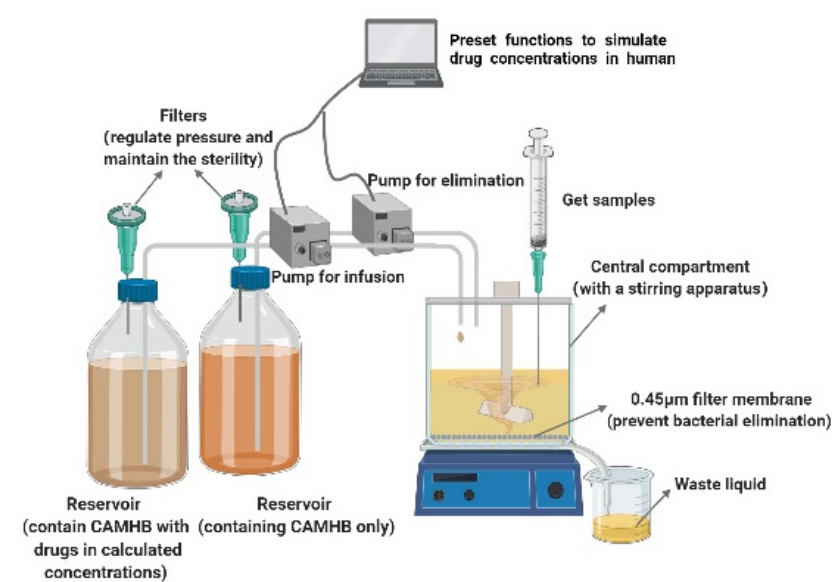

In vitro PK/PD model

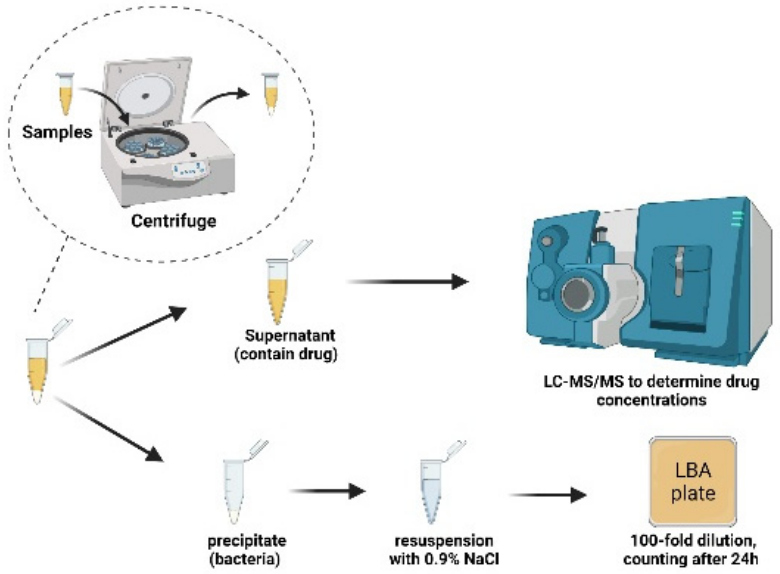

Sample treatment and concentration verification

Figure 3. Experimental apparatus and process diagram.

The bacterial samples were taken with disposable sterile syringe at $0,1,2,3,4,6,8,10$, 12 , and $24 \mathrm{~h}$ after the start of infusion for colony counting and concentration validation. The limit of detection for colony counts was $2 \log _{10} \mathrm{CFU} / \mathrm{mL}$. The dose regimens of single drug or combination of $0.75 \mathrm{mg} / \mathrm{kg}$ via a $2 \mathrm{~h}$ infusion of polymyxin B, and $100 \mathrm{mg}$ via a $2 \mathrm{~h}$ infusion of minocycline were simulated by a two-compartment model, based on the 
pharmacokinetics from Chinese bloodstream infection patients or healthy volunteers [29,47] Each regimen for each bacterial strain was performed three times in parallel. Samples for concentration validation were kept in a $-80^{\circ} \mathrm{C}$ refrigerator until analysis. Both polymyxin $\mathrm{B}$ and minocycline concentrations were determined using previously validated liquid chromatography-tandem mass spectrometry (LC-MS/MS) methods [48,49].

For PK/PD calculation, the AUCs of polymyxin B and minocycline were calculated based on the drug concentrations under different dosage regimens. Then, the PK/PD parameters were obtained from AUC of each drug divided by its MIC alone and MIC in combination when FICI reached the minimum.

\section{Conclusions}

Polymyxin B and minocycline combination showed a synergistic or partial synergistic effect against bla $\mathrm{OXA}_{23} \mathrm{CRAB}$ strains. The in vitro PK/PD model showed that the dosing regimen of $0.75 \mathrm{mg} / \mathrm{kg}$ polymyxin $\mathrm{B}$ combined with $100 \mathrm{mg}$ minocycline via a $2 \mathrm{~h}$ infusion could be a promising treatment option for CRAB bloodstream infections.

Author Contributions: Conceptualization, X.Q. and X.L. (Xiaofen Liu); data curation, X.Q.; formal analysis, X.Q. and X.L. (Xiaofen Liu); funding acquisition, J.Z.; investigation, X.Q. and X.L. (Xiaofen Liu); methodology, J.H., X.H., and X.L. (Xiaofen Liu); project administration, X.L. (Xiaofen Liu); resources, Y.W., Y.F., H.W., X.L. (Xin Li), and B.G.; software, Y.C. and Y.L.; supervision, X.B. and X.L. (Xiaofen Liu); validation, X.Q. and X.B.; visualization, X.Q. and X.B.; writing-review and editing, X.B. and X.L. (Xiaofen Liu) All authors have read and agreed to the published version of the manuscript.

Funding: This research was funded by the National Natural Science Foundation of China (grant number 82173896) and the Shanghai Municipal Science and Technology Commission (grant number 19411964900).

Institutional Review Board Statement: The clinical trial (registration number: NCT01940731) has been approved by the Huashan Institutional Review Board affiliated to Fudan University. Bacterial samples were retrieved from The Culture Collection of Institute of Antibiotics, Huashan Hospital. The Informed Consent Form was waived by the Huashan Institutional Review Board if using strains for further study from The Culture Collection. Personal privacy was not involved in this study.

Informed Consent Statement: Not applicable.

Data Availability Statement: The data that support the findings of this study are available from the corresponding author upon reasonable request.

Conflicts of Interest: The authors declare no conflict of interests.

\section{References}

1. Savoldi, A.; Carrara, E.; Piddock, L.J.V.; Franceschi, F.; Ellis, S.; Chiamenti, M.; Bragantini, D.; Righi, E.; Tacconelli, E. The role of combination therapy in the treatment of severe infections caused by carbapenem resistant gram-negatives: A systematic review of clinical studies. BMC Infect. Dis. 2021, 21, 545. [CrossRef] [PubMed]

2. Jin, L.; Zhao, C.; Li, H.; Wang, R.; Wang, Q.; Wang, H. Clinical profile, prognostic factors, and outcome prediction in hospitalized patients with bloodstream infection: Results from a 10-year prospective multicenter study. Front. Med. 2021, 8, 629671. [CrossRef] [PubMed]

3. Peleg, A.Y.; Hooper, D.C. Hospital-acquired infections due to gram-negative bacteria. N. Engl. J. Med. 2010, $362,1804-1813$. [CrossRef] [PubMed]

4. Falagas, M.E.; Kasiakou, S.K. Toxicity of polymyxins: A systematic review of the evidence from old and recent studies. Crit. Care 2006, 10, R27. [CrossRef] [PubMed]

5. Velkov, T.; Dai, C.; Ciccotosto, G.D.; Cappai, R.; Hoyer, D.; Li, J. Polymyxins for CNS infections: Pharmacology and neurotoxicity. Pharmacol. Ther. 2018, 181, 85-90. [CrossRef]

6. Tam, V.H.; Schilling, A.N.; Vo, G.; Kabbara, S.; Kwa, A.L.; Wiederhold, N.P.; Lewis, R.E. Pharmacodynamics of polymyxin B against Pseudomonas aeruginosa. Antimicrob. Agents Chemother. 2005, 49, 3624-3630. [CrossRef] [PubMed]

7. Cheah, S.E.; Wang, J.; Nguyen, V.T.; Turnidge, J.D.; Li, J.; Nation, R.L. New pharmacokinetic/pharmacodynamic studies of systemically administered colistin against Pseudomonas aeruginosa and Acinetobacter baumannii in mouse thigh and lung infection models: Smaller response in lung infection. J. Antimicrob. Chemother. 2015, 70, 3291-3297.

8. Nang, S.C.; Azad, M.A.K.; Velkov, T.; Zhou, Q.T.; Li, J. Rescuing the last-line polymyxins: Achievements and challenges. Pharmacol. Rev. 2021, 73, 679-728. [CrossRef] 
9. Ma, X.; He, Y.; Yu, X.; Cai, Y.; Zeng, J.; Cai, R.; Lu, Y.; Chen, L.; Chen, C.; Huang, B. Ceftazidime/avibactam improves the antibacterial efficacy of polymyxin B against polymyxin b heteroresistant KPC-2-producing Klebsiella pneumoniae and hinders emergence of resistant subpopulation in vitro. Front. Microbiol. 2019, 10, 2029. [CrossRef]

10. Charretier, Y.; Diene, S.M.; Baud, D.; Chatellier, S.; Santiago-Allexant, E.; van Belkum, A.; Guigon, G.; Schrenzel, J. Colistin heteroresistance and involvement of the PmrAB regulatory system in Acinetobacter baumannii. Antimicrob. Agents Chemother. 2018, 62, e00788-18. [CrossRef]

11. Lashinsky, J.N.; Henig, O.; Pogue, J.M.; Kaye, K.S. Minocycline for the treatment of multidrug and extensively drug-resistant $A$. baumannii: A review. Infect. Dis. Ther. 2017, 6, 199-211. [CrossRef]

12. Bishburg, E.; Bishburg, K. Minocycline-An old drug for a new century: Emphasis on methicillin-resistant Staphylococcus aureus (MRSA) and Acinetobacter baumannii. Int. J. Antimicrob. Agents 2009, 34, 395-401. [CrossRef]

13. Greig, S.L.; Scott, L.J. Intravenous minocycline: A review in Acinetobacter infections. Drugs 2016, 76, 1467-1476. [CrossRef] [PubMed]

14. Garrido-Mesa, N.; Zarzuelo, A.; Gálvez, J. Minocycline: Far beyond an antibiotic. Br. J. Pharmacol. 2013, 169, 337-352. [CrossRef] [PubMed]

15. Alfouzan, W.A.; Noel, A.R.; Bowker, K.E.; Attwood, M.L.G.; Tomaselli, S.G.; MacGowan, A.P. Pharmacodynamics of minocycline against Acinetobacter baumannii studied in a pharmacokinetic model of infection. Int. J. Antimicrob. Agents 2017, 50, 715-717. [CrossRef] [PubMed]

16. Goff, D.A.; Bauer, K.A.; Mangino, J.E. Bad bugs need old drugs: A stewardship program's evaluation of minocycline for multidrug-resistant Acinetobacter baumannii infections. Clin. Infect. Dis. 2014, 59 (Suppl. S6), S381-S387. [CrossRef] [PubMed]

17. He, S.; He, H.; Chen, Y.; Chen, Y.; Wang, W.; Yu, D. In vitro and in vivo analysis of antimicrobial agents alone and in combination against multi-drug resistant Acinetobacter baumannii. Front. Microbiol. 2015, 6, 507. [CrossRef] [PubMed]

18. Bowers, D.R.; Cao, H.; Zhou, J.; Ledesma, K.R.; Sun, D.; Lomovskaya, O.; Tam, V.H. Assessment of minocycline and polymyxin B combination against Acinetobacter baumannii. Antimicrob. Agents Chemother. 2015, 59, 2720-2725. [CrossRef]

19. Aranzana-Climent, V.; Buyck, J.M.; Smani, Y.; Pachón-Diaz, J.; Marchand, S.; Couet, W.; Grégoire, N. Semi-mechanistic PK/PD modelling of combined polymyxin B and minocycline against a polymyxin-resistant strain of Acinetobacter baumannii. Clin. Microbiol. Infect. 2020, 26, 1254.e9-1254.e15. [CrossRef]

20. Zhang, Y.; Chen, F.; Sun, E.; Ma, R.; Qu, C.; Ma, L. In vitro antibacterial activity of combinations of fosfomycin, minocycline and polymyxin B on pan-drug-resistant Acinetobacter baumannii. Exp. Ther. Med. 2013, 5, 1737-1739. [CrossRef]

21. Bian, X.; Liu, X.; Zhang, X.; Li, X.; Zhang, J.; Zheng, H.; Song, S.; Li, X.; Feng, M. Epidemiological and genomic characteristics of Acinetobacter baumannii from different infection sites using comparative genomics. BMC Genom. 2021, 22, 530. [CrossRef]

22. LaPlante, K.L.; Rybak, M.J.; Leuthner, K.D.; Chin, J.N. Impact of Enterococcus faecalis on the bactericidal activities of arbekacin, daptomycin, linezolid, and tigecycline against methicillin-resistant Staphylococcus aureus in a mixed-pathogen pharmacodynamic model. Antimicrob. Agents Chemother. 2006, 50, 1298-1303. [CrossRef]

23. Lyu, C.; Zhang, Y.; Liu, X.; Wu, J.; Zhang, J. Clinical efficacy and safety of polymyxins based versus non-polymyxins based therapies in the infections caused by carbapenem-resistant Acinetobacter baumannii: A systematic review and meta-analysis. BMC Infect. Dis. 2020, 20, 296. [CrossRef]

24. Beganovic, M.; Daffinee, K.E.; Luther, M.K.; LaPlante, K.L. Minocycline alone and in combination with polymyxin b, meropenem, and sulbactam against carbapenem-susceptible and -resistant Acinetobacter baumannii in an in vitro pharmacodynamic model. Antimicrob. Agents Chemother. 2021, 65, e01680-20. [CrossRef] [PubMed]

25. Bian, X.; Liu, X.; Hu, F.; Feng, M.; Chen, Y.; Bergen, P.J.; Li, J.; Li, X.; Guo, Y.; Zhang, J. Pharmacokinetic/pharmacodynamic based breakpoints of polymyxin B for bloodstream infections caused by multidrug-resistant gram-negative pathogens. Front. Pharmacol. 2022, 12, 785893. [CrossRef] [PubMed]

26. Duan, N.; Sun, L.; Huang, C.; Li, H.; Cheng, B. Microbial distribution and antibiotic susceptibility of bloodstream infections in different intensive care units. Front. Microbiol. 2021, 12, 792282. [CrossRef]

27. Bian, X.; Liu, X.; Feng, M.; Bergen, P.J.; Li, J.; Chen, Y.; Zheng, H.; Song, S.; Zhang, J. Enhanced bacterial killing with colistin/sulbactam combination against carbapenem-resistant Acinetobacter baumannii. Int. J. Antimicrob. Agents 2021, 57, 106271 [CrossRef] [PubMed]

28. Bian, X.; Liu, X.; Chen, Y.; Chen, D.; Li, J.; Zhang, J. Dose optimization of colistin combinations against carbapenemresistant Acinetobacter baumannii from patients with hospital-acquired pneumonia in China by using an in vitro pharmacokinetic/pharmacodynamic model. Antimicrob. Agents Chemother. 2019, 63, e01989-18. [CrossRef]

29. He, J.; Liu, S.; Xia, P.; Chen, Y.; Tang, M.; Dai, Q.; Xiong, L. Pharmacokinetics of single and multiple intravenous doses of minocycline hydrochloride. Chin. J. New Drugs 2006, 15, 824-827.

30. Welling, P.G.; Shaw, W.R.; Uman, S.J.; Tse, F.L.; Craig, W.A. Pharmacokinetics of minocycline in renal failure. Antimicrob. Agents Chemother. 1975, 8, 532-537. [CrossRef]

31. Macdonald, H.; Kelly, R.G.; Allen, E.S.; Noble, J.F.; Kanegis, L.A. Pharmacokinetic studies on minocycline in man. Clin. Pharmacol. Ther. 1973, 14, 852-861. [CrossRef] [PubMed]

32. MINOCIN@Minocycline for Injection $100 \mathrm{mg} /$ vial. Available online: https://dailymed.nlm.nih.gov/dailymed/fda/fdaDrugXsl. cfm?setid=e415c323-8219-464b-9e3e-72c5a796cdaa (accessed on 1 January 2022). 
33. Kubin, C.J.; Nelson, B.C.; Miglis, C.; Scheetz, M.H.; Rhodes, N.J.; Avedissian, S.N.; Cremers, S.; Yin, M.T. Population pharmacokinetics of intravenous polymyxin B from clinical samples. Antimicrob. Agents Chemother. 2018, 62, e01493-17. [CrossRef] [PubMed]

34. Trimble, M.J.; Mlynárčik, P.; Kolář, M.; Hancock, R.E. Polymyxin: Alternative mechanisms of action and resistance. Cold Spring Harb. Perspect. Med. 2016, 6, a025288. [CrossRef] [PubMed]

35. Asadi, A.; Abdi, M.; Kouhsari, E.; Panahi, P.; Sholeh, M.; Sadeghifard, N.; Amiriani, T.; Ahmadi, A.; Maleki, A.; Gholami, M. Minocycline, focus on mechanisms of resistance, antibacterial activity, and clinical effectiveness: Back to the future. J. Glob. Antimicrob. Resist. 2020, 22, 161-174. [CrossRef] [PubMed]

36. Morozumi, M.; Okada, T.; Tajima, T.; Ubukata, K.; Iwata, S. Killing kinetics of minocycline, doxycycline and tosufloxacin against macrolide-resistant Mycoplasma pneumoniae. Int. J. Antimicrob. Agents 2017, 50, 255-257. [CrossRef] [PubMed]

37. Athamna, A.; Athamna, M.; Medlej, B.; Bast, D.J.; Rubinstein, E. In vitro post-antibiotic effect of fluoroquinolones, macrolides, beta-lactams, tetracyclines, vancomycin, clindamycin, linezolid, chloramphenicol, quinupristin/dalfopristin and rifampicin on Bacillus anthracis. J. Antimicrob. Chemother. 2004, 53, 609-615. [CrossRef]

38. Zhanel, G.G.; Homenuik, K.; Nichol, K.; Noreddin, A.; Vercaigne, L.; Embil, J.; Gin, A.; Karlowsky, J.A.; Hoban, D.J. The glycylcyclines: A comparative review with the tetracyclines. Drugs 2004, 64, 63-88. [CrossRef] [PubMed]

39. Zavascki, A.P.; Nation, R.L. Nephrotoxicity of polymyxins: Is there any difference between colistimethate and polymyxin B? Antimicrob. Agents Chemother. 2017, 61, e02319-16. [CrossRef]

40. Liu, X.; Chen, Y.; Yang, H.; Li, J.; Yu, J.; Yu, Z.; Cao, G.; Wu, X.; Wang, Y.; Wu, H.; et al. Acute toxicity is a dose-limiting factor for intravenous polymyxin B: A safety and pharmacokinetic study in healthy Chinese subjects. J. Infect. 2021, 82, 207-215. [CrossRef]

41. Hu, J.; Kholmukhamedov, A.; Lindsey, C.C.; Beeson, C.C.; Jaeschke, H.; Lemasters, J.J. Translocation of iron from lysosomes to mitochondria during acetaminophen-induced hepatocellular injury: Protection by starch-desferal and minocycline. Free Radic. Biol. Med. 2016, 97, 418-426. [CrossRef]

42. Dai, C.; Ciccotosto, G.D.; Cappai, R.; Wang, Y.; Tang, S.; Xiao, X.; Velkov, T. Minocycline attenuates colistin-induced neurotoxicity via suppression of apoptosis, mitochondrial dysfunction and oxidative stress. J. Antimicrob. Chemother. 2017, 72, 1635-1645. [CrossRef]

43. Fragkou, P.C.; Poulakou, G.; Blizou, A.; Blizou, M.; Rapti, V.; Karageorgopoulos, D.E.; Koulenti, D.; Papadopoulos, A.; Matthaiou, D.K.; Tsiodras, S. The Role of minocycline in the treatment of nosocomial infections caused by multidrug, extensively drug and pandrug resistant Acinetobacter baumannii: A systematic review of clinical evidence. Microorganisms 2019, 7, 159. [CrossRef] [PubMed]

44. Dai, C.; Xiao, X.; Li, J.; Ciccotosto, G.D.; Cappai, R.; Tang, S.; Schneider-Futschik, E.K.; Hoyer, D.; Velkov, T.; Shen, J. Molecular mechanisms of neurotoxicity induced by polymyxins and chemoprevention. ACS Chem. Neurosci. 2019, 10, 120-131. [CrossRef] [PubMed]

45. Tsuji, B.T.; Pogue, J.M.; Zavascki, A.P.; Paul, M.; Daikos, G.L.; Forrest, A.; Giacobbe, D.R.; Viscoli, C.; Giamarellou, H.; Karaiskos, I.; et al. International consensus guidelines for the optimal use of the polymyxins: Endorsed by the American College of Clinical Pharmacy (ACCP), European Society of Clinical Microbiology and Infectious Diseases (ESCMID), Infectious Diseases Society of America (IDSA), International Society for Anti-infective Pharmacology (ISAP), Society of Critical Care Medicine (SCCM), and Society of Infectious Diseases Pharmacists (SIDP). Pharmacotherapy 2019, 39, 10-39. [PubMed]

46. Neu, H.C. Mecillinam-an amidino penicillin which acts synergistically with other beta-lactam compounds. J. Antimicrob. Chemother. 1977, 3 (Suppl. SB), 43-52. [CrossRef]

47. Zhang, J.; Zhang, S.; Sun, Z.; Han, B.; Kong, Y.; Zhou, L.; Zhu, Z.; Luo, Y.; Zhang, X. Population pharmacokinetics of polymyxin B in patients with sepsis. Chin. Pharm. J. 2021, 56, 744-748.

48. Liu, X.; Yu, Z.; Wang, Y.; Wu, H.; Bian, X.; Li, X.; Fan, Y.; Guo, B.; Zhang, J. Therapeutic drug monitoring of polymyxin B by LC-MS/MS in plasma and urine. Bioanalysis 2020, 12, 845-855. [CrossRef]

49. Patel, D.S.; Sharma, N.; Patel, M.C.; Patel, B.N.; Shrivastav, P.S.; Sanyal, M. Analysis of a second-generation tetracycline antibiotic minocycline in human plasma by LC-MS/MS. Bioanalysis 2011, 3, 2177-2194. [CrossRef] [PubMed] 